\title{
Managing nasal valve compromise patients with nasal dilators: objective vs. subjective parameters*
}

\author{
Garyfalia Lekakis ${ }^{1 \#}$, Emily Dekimpe ${ }^{1 \#}$, Brecht Steelant ${ }^{2}$, Peter W. Hellings $s^{1,23,4}$ \\ 'Department of Otorhinolaryngology, Head and Neck surgery, University Hospitals Leuven, Leuven, Belgium \\ 2 Department of Microbiology and Immunology, KU Leuven, Belgium \\ Department of Otorhinolaryngology, University of Ghent, Belgium \\ ${ }^{4}$ Department of Otorhinolaryngology, Academic Medical Centre, Amsterdam, The Netherlands
}

Rhinology 54: 348-354, 2016

DOI:10.4193/Rhino16.192

* Received for publication:

June 12, 2016

Accepted: July 7, 2016

\# shared first authorship

\begin{abstract}
Introduction: Patients suffering from nasal obstruction due to nasal valve compromise may benefit from a nasal dilator. Several devices for widening of the external/internal nasal valve region can be applied endonasally (Airmax ${ }^{\circledR}, \mathrm{Nasanita}^{\circledR}$, Nozovent ${ }^{\circledR}$ ) or externally (Breathe Right ${ }^{\circledR}$ ).
\end{abstract}

Materials and methods: 100 patients suffering from nasal obstruction due to external or internal nasal valve compromise were involved in this study. All patients were evaluated for nasal obstruction with visual analogue scores (VAS) and peak nasal inspiratory flow (PNIF) measurements before and after the application of 4 nasal dilators. They were offered to choose 2 out of 4 for a trial period of 1 month. Subsequently, patients were reassessed and asked about their willingness to continue using the dilators, as well as the reasons for discontinuation.

Results: There was a significant decrease of VAS scores and improvement in PNIF with the dilators in situ compared to baseline. After 4 weeks, $67 \%$ of patients were willing to continue using at least one of the chosen dilators. The reasons for discontinuation were local irritation, inappropriate fit, preference for a permanent solution like surgery, and no relief of symptoms.

Conclusion: Nasal dilators represent a valuable option in the therapeutic approach of nasal valve compromise, with endonasal dilators achieving higher increase in PNIF in comparison with external nasal dilators.

Key words: nasal dilator, nasal valve compromise, Airmax, Breathe Right, Nasanita, Nozovent

\section{Introduction}

Symptoms of nasal obstruction have an effect on sleep, exercise, and can interfere with the patient's quality of life. Nasal valve compromise (NVC) has been recognized as an important source of nasal obstruction ${ }^{(1)}$. In many individuals, valve effects may equal or surpass septal deviation as the primary cause of nasal airflow obstruction ${ }^{(2)}$ and therefore nasal valve function should be assessed in all patients that present with nasal obstruction. NVC can be due to congenital reasons, trauma, previous surgery, facial nerve palsy, and/or weakness of the nasal cartilages, or intrinsic aging.

The nasal valves have been proposed to be a major regulator of nasal airflow, preventing airflow from exceeding the capacity to warm and humidify inspired air ${ }^{(3)}$. By means of having the smallest cross-sectional area of the entire respiratory tract, the nasal valves are the primary location of the greatest nasal airflow resistance ${ }^{(4)}$. As air enters this constricted segment of the airway, acceleration of the airflow occurs. This results in a drop in intraluminal pressure by the Bernoulli principle. The pressure drop can lead to collapse of this segment of the airway during inspiration. Whether or not this force leads to actual symptomatic collapse of the lateral nasal wall, depends on the intrinsic stability and on the pressure changes to which it is subjected during quite and forced inspiration ${ }^{(5)}$. 
In case of NVC, surgery in the form of functional rhinoplasty is often advocated involving a single or combined surgical techniques to optimise the size and function of the nasal valve. The surgical philosophies usually fall into the following broad categories: Increasing either the rigidity and/or the diameter of the nasal valve(6). In principle the existing surgical techniques for treatment of the nasal valve region improve the ability to overcome a negative pressure drop. Whether that is due to increasing the diameter of the region or increasing the rigidity of the wall or both is unclear.

Additionally in those patients where surgery is neither primarily indicated nor desired, non-surgical options should be discussed. The use of nasal dilators is a relatively new treatment modality for nasal obstruction secondary to NVC.

This study was performed to compare the subjective and objective benefits between four different nasal dilators in adults with NVC, as well as the patients' tolerability and preference for these devices. Testing different nasal dilators regarding their ability to stent the anterior nasal airway and subsequent increase in peak nasal inspiratory flow (PNIF), may aid in gaining knowledge of whether or not there is therapeutic superiority in using one type of device over the others, in order to ameliorate nasal obstruction.

\section{Materials and methods}

100 patients with nasal valve compromise as the single etiologic factor of nasal obstruction were selected for participation in this prospective non-randomized interventional study, running from September 2014 until December 2015 in the Rhinology Clinic of the Otorhinolaryngology Department at the University Hospital of Leuven, Belgium.

This study was registered at ClinicalTrials.gov (NCT02196389). The Medical Ethics Committee on Clinical Investigations at the University Hospitals of Leuven approved the study, and informed consent was obtained from all subjects.

\section{Participants}

The surgeons conducting the study (PWH \& GL) diagnosed nasal valve compromise based on clinical examination that included Cottle or modified Cottle maneuver ${ }^{(7)}$, dynamic lateral wall or alar rim collapse on mild to moderate inspiratory effort, middle vault narrowing, or narrow internal nasal valve on anterior rhinoscopy/endoscopy. The absence of significant concomitant mucosal disease, or any endo-nasal anatomic malformation, was confirmed by nasal endoscopy, hence excluding patients with rhinosinusitis, nasal polyposis or moderate/significant septal deviation, which would contribute to the breathing impairment. Among the exclusion criteria was chronic airway disease of the lower respiratory tract such as asthma and/or COPD (chronic obstructive airway disease), which would interfere with a reliable PNIF result ${ }^{(8)}$. A thorough medical history was taken, focusing on nasal medications and previous nasal surgery.

\section{Objective assessment of airflow}

Nasal flow was evaluated using the portable inspiratory flow meter (Clement Clarke International, Essex, UK) while the patient was seated with an attached anesthetic mask. A soft facemask was used to ensure a tight seal and to avoid distortion of the nose or compression on the external nares. Patients were instructed to take a maximal forced inspiratory effort through the nose with the mouth closed. Three consecutive measurements with an inter-measurement variability of less than $10 \%$ were recorded, and the best result was noted, as in previous studies ${ }^{(9)}$. This value of PNIF was considered the baseline value.

\section{Patient reported nasal obstruction}

The selected patients were asked to rate overall their nasal obstruction using a VAS score from 0 to $100 \mathrm{~mm}$, where 0 indicates no obstruction and $100 \mathrm{~mm}$ indicates total obstruction. A number was then obtained from 0 to 100 for severity of nasal obstruction at base line.

\section{Intervention}

3 endo-nasal dilators (Nasanita by Siemens \& Co, Germany; Airmax by Airmax BV, The Netherlands, Nozovent by Pharma-

Table 1. Patients' demographics

\begin{tabular}{|c|c|c|}
\hline \multirow{2}{*}{ Number of patients } & Baseline visit ( $n$ ) & 100 \\
\hline & Follow-up visit (n) & 84 \\
\hline \multirow{2}{*}{ Sex (\%) } & Men & 54,0 \\
\hline & Women & 46,0 \\
\hline \multirow[t]{6}{*}{ Age (\%) } & $<30 y$ & 17 \\
\hline & $30 y-39 y$ & 18 \\
\hline & $40 y-49 y$ & 24 \\
\hline & $50 y-59 y$ & 25 \\
\hline & $\geq 60 y$ & 16 \\
\hline & Mean age $\pm S D$ & $46 \pm 14$ \\
\hline \multirow[t]{6}{*}{ Presence of allergies (\%) } & No allergies & 68 \\
\hline & Housedustmite & 14 \\
\hline & Grass & 8 \\
\hline & Trees & 7 \\
\hline & Animal & 4 \\
\hline & Other & 9 \\
\hline \multirow[t]{5}{*}{ Duration of nasal symptoms (\%) } & $<5 y$ & 26 \\
\hline & $5 y<10 y$ & 19 \\
\hline & $10 y<20 y$ & 26 \\
\hline & $20 y<30 y$ & 11 \\
\hline & $>30 y$ & 16 \\
\hline \multirow[t]{5}{*}{ Time frame of nasal symptoms (\%) } & During excercise & 22 \\
\hline & Night time & 55 \\
\hline & During the day & 14 \\
\hline & Always & 33 \\
\hline & Unknown & 2 \\
\hline \multirow[t]{3}{*}{ Location of nasal obstruction (\%) } & Left side & 30 \\
\hline & Right side & 16 \\
\hline & Bilateral & 56 \\
\hline \multirow[t]{7}{*}{ Previous nasal intervention (\%) } & Septoplasty & 21 \\
\hline & FESS & 13 \\
\hline & Turbinate surgery & 13 \\
\hline & Septorhinoplasty & 8 \\
\hline & Rhinoplasty & 3 \\
\hline & Unknown intervention & 13 \\
\hline & No previous intervention & 29 \\
\hline
\end{tabular}




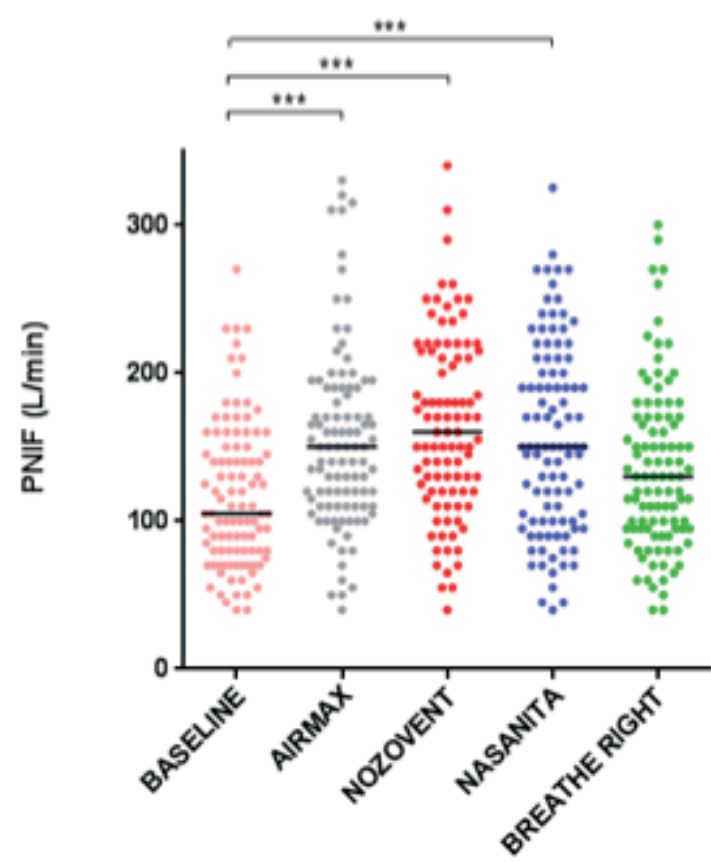

\section{Device}

PNIF (L/min)

P-value

\begin{tabular}{lll}
\hline Baseline & $105(80-150)$ & \\
Airmax & $150(110-190)$ & $\mathrm{P}<.001^{*}$ \\
Nozovent & $160(120-215)$ & $\mathrm{P}<.001^{*}$ \\
Nasanita & $150(100-208)$ & $\mathrm{P}<.001^{*}$ \\
Breathe Right & $130(95-170)$ & $\mathrm{NS}^{*}$
\end{tabular}

Data presented as median (IQR). Kruskal-Wallis test with posthoc test. * Signficant difference vs. Baseline PNIF.

Figure 1A. PNIF values at baseline vs with dilators.

cure $A B$, Sweden) and 1 external dilator (Breathe Right by Glaxo Smith Kline, UK) were applied on all patients following randomization of the order in which dilators were presented. For each nasal dilator and while the device was in place, a new VAS score was assessed on nasal obstruction and satisfaction for the device. Subsequently a PNIF measurement was taken with the device still in the nose.

Finally the patients were asked to choose 2 out of the 4 devices they tried in the clinic, for personal use. They were instructed to use one dilator for the first week and the other for the following week. After that period, they were free to use the device of their choice, until a phase of four weeks was complete. The patients were obliged to keep a diary during this time. They were handed a leaflet of printed entries for 30 days, along with the names of the devices. They had to complete the form, each and every time they were using a nasal dilator, and for every activity sepa-

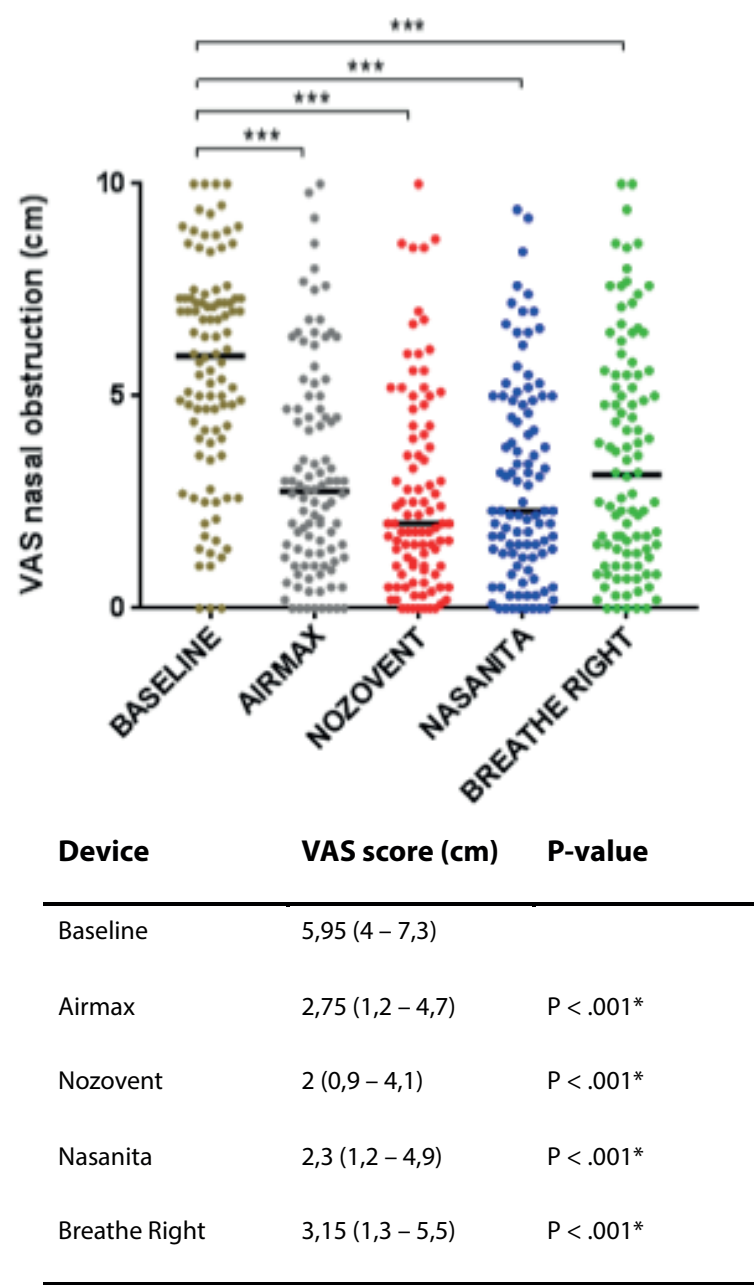

Data presented as median (IQR). Kruskal-Wallis test with posthoc test. * Signficant difference vs. Baseline VAS score.
Figure 1B). VAS scores on nasal obstruction at baseline vs with dilators. $0 / 10=$ no complaints, $10 / 10=$ very bad complaints

rately. The dilators could be used during daily activities, exercise, or sleeping.

During the follow up visit, patients gave a VAS score on general satisfaction on each device, and were asked questions regarding usage, tolerability, preference, intention to use in the future, or reasons for discontinuation.

\section{Statistical analysis}

Data were analyzed with GraphPad Prism 5 software (GraphPad Software, La Jolla, CA, USA). Differences between groups were analyzed by using the 2-tailed unpaired t test or Mann-Whitney $U$ test. Data are presented as means and SDs or medians (interquartile ranges). The Kruskal-Wallis test with post hoc analysis was used to compare multiple groups. Categorical values were compared by using the Fisher exact test. Values were considered significantly different at a $\mathrm{P}<0.05$. 
Table 2. PNIF improvement per dilator.

\begin{tabular}{|lcl|}
\hline \multicolumn{1}{|c}{ Device } & $\begin{array}{c}\text { \%PNIF } \\
\text { improvement }\end{array}$ & P-value \\
\hline Airmax & $31(11-60)$ & $\mathrm{P}<.001^{*}$ \\
\hline Nozovent & $34(17-70)$ & $\mathrm{P}<.001^{*}$ \\
\hline Nasanita & $32(11-63)$ & $\mathrm{P}<.001^{*}$ \\
\hline Breathe Right & $13(0-29)$ & \\
\hline
\end{tabular}

Data presented as median (IQR). Kruskal-Wallis test with post-hoc test. * Signficant difference vs. Breathe Right.

Table 3. Number of selections per dilator.

\begin{tabular}{|lcc|}
\hline Number of & $\begin{array}{c}\text { Nelections } \\
\text { Airmax }\end{array}$ & $\%$ \\
\hline Nasanita & 68 & 34,9 \\
\hline Breathe Right & 54 & 27,7 \\
\hline Nozovent & 44 & 22,6 \\
\hline
\end{tabular}

Table 4. Reasons for discontinuation for all dilators.

\begin{tabular}{|lc|}
\hline Reason & $\%$ \\
\hline Local irritation & 31 \\
\hline Inappropriate fit & 38 \\
\hline Prefers permanent solution with surgery & 8 \\
\hline No relief of symptoms & 20 \\
\hline Other (e.g. Difficulty with placement) & 3 \\
\hline
\end{tabular}

\section{Results}

\section{Patient's characteristics}

100 patients with nasal obstruction primarily caused by NVC were recruited in this study. All patients' demographics are presented in Table 1.

\section{Improvement of PNIF with nasal dilators}

Median baseline PNIF values were 105 (80-150) I/min, with the median PNIF achieved by each dilator demonstrated in Figure $1 \mathrm{~A}$. The median percentage of PNIF increase per dilator in comparison with base line values is shown in Table 2 .

Improvement of subjective nasal obstruction with nasal dilators VAS scores on nasal obstruction with the dilators in situ were significantly decreased compared with the baseline values (Figure 1B).

\section{Patients' preference of nasal dilators}

Table 3 demonstrates the number of selections per dilator by 100 patients at the first visit. In total there were 195 selections as 5 patients chose only one dilator. In $85 \%$ of the total 195 selections made by the patients, the selection for at least 1 dilator was associated with the highest measuremnt in PNIF at baseline visit.

\section{Patient's satisfaction and reasons for discontinuation} Regarding satisfaction during the follow-up visit, and after 4 weeks of usage, $67 \%$ of the patients are willing to keep using at least one of the chosen dilators and 33\% prefer to discontinue (Figure 2).

The satisfaction rates for each device are shown in Figure 3. The reasons for discontinuation were primarily local irritation, inappropriate fit, preference for a permanent solution like surgery, and no relief of symptoms (Table 4). The reasons for discontinuation per dilator are shown in Figure 4.

\section{Discussion}

The present study compares the ability of one external nasal dilator, and three endo-nasal dilators to produce improvements on subjective and objective parameters in 100 consecutive patients with NVC. The study was designed in order to discover the efficacy of mechanical stents and any beneficial advantage of one device over the others, when treating with non-surgical options, nasal obstruction in the context of valvular pathology. Numerous studies have analyzed the benefits of various nasal dilators on healthy individuals ${ }^{(10-12)}$, healthy athletes ${ }^{(13,14)}$, snorers ${ }^{(15-17)}$, patients with obstructive sleep apnoea(18,19), patients with sleep-disordered breathing ${ }^{(20)}$, pregnant women ${ }^{(21)}$, cancer patients ${ }^{(22)}$ and more recently on children ${ }^{(23,24)}$.

Roithmann et al. studied the effects of external nasal dilators (END) on the cross sectional area of the nasal valve in patients with nasal obstruction following rhinoplasty ${ }^{(25)}$. Riechelmann et al. tested 10 healthy controls and 10 patients with alar collapse by using an internal nasal dilator (IND). They concluded that an IND effectively enlarged the region of the ENV, abolished alar collapse and improved nasal airflow ${ }^{(26)}$. Gruber et al. evaluated and classified valvular nasal obstruction using external nasal strips $^{(27)}$. Hellings \& Trenité reported on 30 patients with ENV dysfunction that used an IND, and concluded that this represents a good alternative to surgery ${ }^{(28)}$.

Often these studies present limitations, such as restricted number of patients ${ }^{(10,15)}$ or absence of relevant objective data. Repeatedly, the reported improvement of nasal flow achieved by the dilators is demonstrated by either acoustic rhinometry ${ }^{(10,13,29)}$ or rhinomanometry ${ }^{(12,30,31)}$. Although these tests were considered the most favored objective tests to measure nasal patency, studies regarding their validity are equivocal ${ }^{(32,33)}$. To that effect the 


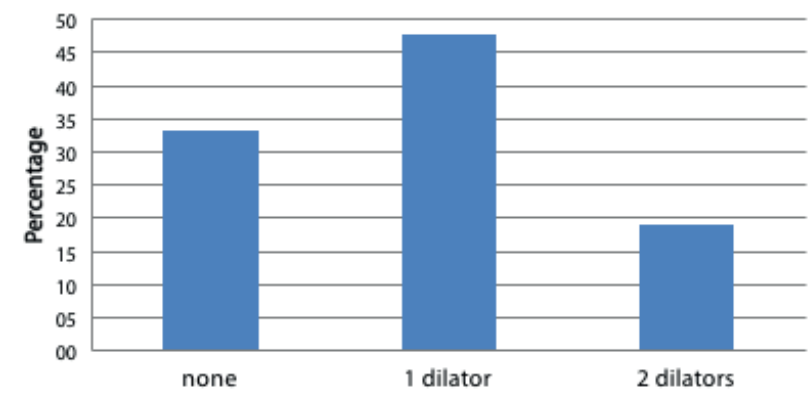

Figure 2. Patients willing to use the dilators after 4 weeks.

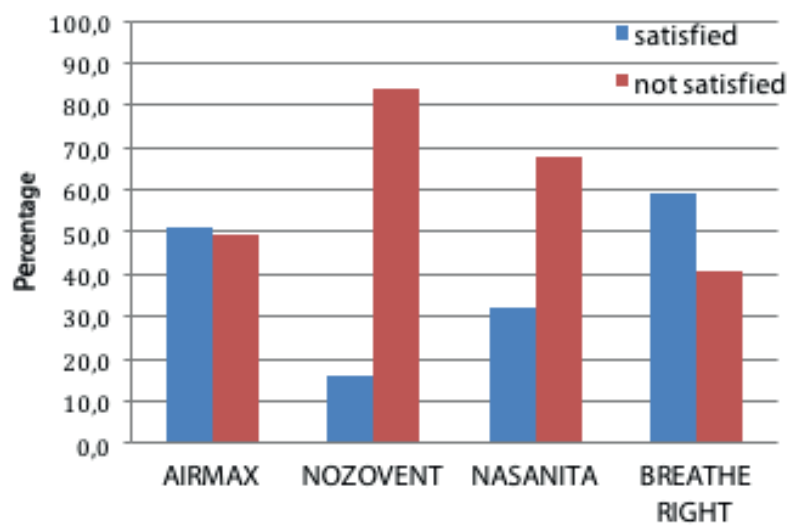

Figure 3. Patient satisfaction after 4 weeks.

Blue $=$ satisfied, red $=$ not satisfied.

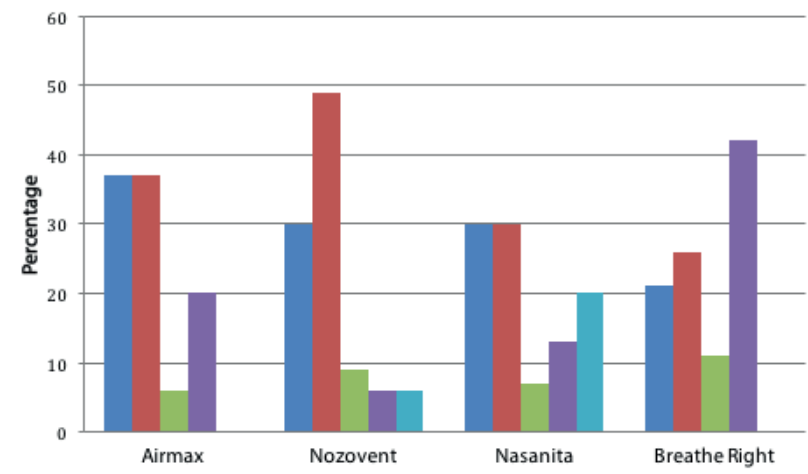

Figure 4. Reasons for discontinuation per dilator.

Dark blue $=$ local irritation, red $=$ inappropriate fit , green $=$ prefers permanent solution with surgery, purple $=$ no relief of symptoms, light blue $=$ other (ex. difficult to place).

general use of these objective measures in clinical settings has been discouraged owing to their poor correlation with subjective outcomes ${ }^{(1)}$.

In a systematic review and expert consensus statement that was achieved in 2010, was indicated that the use of alternative mechanical stents, such as external nasal dilator strips or inter- nal nasal dilators, has a role in some patients with nasal valve compromise ${ }^{(1)}$. In the same document it is noted that, although patients who are poor surgical candidates because of underlying medical comorbidities or those who do not wish to undergo surgery may find the use of these mechanical stents helpful to treat the lateral nasal wall collapse, these devices are not always effective. Despite the fact that the use of nasal dilators has become more common in the recent years, there is indeed lack of clinical evidence in the literature, regarding their efficacy in targeted groups of patients with the diagnosis of NVC.

At present, patients with nasal valve dysfunction are being proposed to undergo either corrective valve surgery or a conservative approach using nasal dilators, without surgeons being able to give an estimate satisfaction rate of the latter.

For this study we utilised subjective and objective parameters. The subjective parameters were the VAS scores achieved by the patients. The objective test used, was the PNIF. A European consensus group recently stated that PNIF measurements are the best-validated technique for the evaluation of nasal flow through the nose $\mathrm{e}^{(34)}$. Additionally, evidence from the literature is emerging, that PNIF is the most robust tool to assess improvement in collapsibility, and aligns with improvements in subjective results, in patients with ENV deficiency that undergo rhinoplasty ${ }^{(35)}$.

As it is highlighted in the results, the increase in PNIF was witnessed across the range of all dilators tested. It is however notable, that the increase in PNIF was statistically significant with all the IND and not with the END. Furthermore in $85 \%$ of the total number of selections made (195 in total), the patient' $s$ choice for at least 1 dilator was associated with the highest measurement in PNIF at baseline. A statistically significant drop of the VAS scores for nasal obstruction for each and every dilator was also observed. These findings support the concept that PNIF measurements are in line with subjective results such as VAS scores. Nasal dilators are designed to alter the nasal geometry of the region of the external and internal nasal valve, which contributes significantly to increased resistance in the upper airway. It has been suggested in the literature that changes in the nasal geometry of the anterior part of the nose by an END affects the pattern of nasal airflow and transforms it into a laminar pattern ${ }^{(36)}$. Changing the nasal geometry with a nasal dilator is achieved by widening the nasal passage and by making structural components less prone to collapse. Internal stenting of the alae has also been shown to inhibit collapse at the lateral nasal wall and to increase PNIF in previous studies ${ }^{(37,38)}$. Similarly to the effects of functional rhinoplasy, when making the structural components of the ENV more rigid, other components of the lateral nasal wall such as the INV, may be affected ${ }^{(35)}$. The effects of the nasal dilators cannot be isolated, and it is likely that affect components of both INV and ENV simultaneously. The current study demonstrates that after 4 weeks of usage, 
$67 \%$ of patients with the diagnosis of NVC were satisfied with at least one of the chosen nasal dilators and willing to continue using it indefinitely. It is worth here drawing our attention to the fact that $58 \%$ of patients had a history of previous nasal surgery (septoplasty, turbinate reduction, rhinoplasty, or functional endoscopic sinuses surgery) and were not keen on a surgical intervention. Considering also the tendency towards minimally invasive techniques, as patients want a "quick fix" with no downtime and even reduced costs, nasal dilators can be considered fit for purpose.

Concurrently, $33 \%$ of patients preferred to discontinue using the dilators. A cohort of these patients with NVC, were considering surgery as an option, but wanted to experience the benefits of the mechanical stent beforehand. It was explained to them, that in a sense, the effects of the nasal dilator are mimicking the results of the surgical intervention. During the consultation and having established an accurate diagnosis, it is important to offer all therapeutic options at hand. Nasal dilators not only can be offered as a less invasive treatment option, but also as a temporary solution, preparing the patient for the functional results of the surgery that lies ahead.

\section{Conclusion}

This study puts to the test four different nasal dilators, in a 100 patients with NVC as the primary cause of nasal obstruction. Internal nasal dilators were associated with statistically significant improvement on PNIF values, but not the external nasal dilators.
However all dilators decreased the VAS scores for nasal obstruction on all patients.

Nasal anatomy and physiology is unique across individuals, and nasal valve dysfunction should always be treated with a tailored regimen specific to the individual deformities. As we move towards a better understanding of the dynamics of the nasal skeleton and the complex nature of rhinoplasty for repair of the weak lateral nasal wall, we should keep in mind that nonsurgical options are also available, and that can play a role in our diagnostic and therapeutic strategies.

\section{Authorship contribution}

GL: recruitment of patients, execution of methodology, and writing of the manuscript. ED: execution of methodology and statistical analysis. BS: statistical analysis. PWH: study concept, recruitment of patients, and senior review of the manuscript.

\section{Conflict of interest}

The authors have no conflict of interest in relation to this study and the results described in the manuscript. This was an academic study without financial support of the companies involved (Airmax, Siemens, Glaxo Smith Kline, and Pharmacure). The devices Airmax, Nasanita, and Nozovent were kindly donated by the companies Airmax, Siemens, and Pharmacure respectively. The external nasal strips, named Breathe Right, were purchased by the senior investigator (P.W. Hellings), for the purposes of the study.

\section{References}

1. Rhee JS, Weaver EM, Park SS, Baker SR, Hilger PA, Kriet JD, et al. Clinical consensus statement: Diagnosis and management of nasal valve compromise. Otolaryngol Head Neck Surg. 2010 Jul;143(1):48-59

2. Constantian MB, Clardy $\mathrm{RB}$. The relative importance of septal and nasal valvular surgery in correcting airway obstruction in primary and secondary rhinoplasty. Plast Reconstr Surg. 1996 Jul;98(1):38-54; discussion 55-8.

3. Spielmann PM, White PS, Hussain SSM Surgical techniques for the treatment of nasal valve collapse: a systematic review. Laryngoscope. 2009 Jul;119(7):1281-90.

4. Adamson P, Smith O, Cole P. The effect of cosmetic rhinoplasty on nasal patency. Laryngoscope. 1990 Apr;100(4):357-9.

5. Kim DW, Rodriguez-Bruno K. Functional rhinoplasty. Facial Plast Surg Clin North Am. 2009 Feb;17(1):115-31, vii.

6. Rhee JS, Kimbell JS. The nasal valve dilemma: the narrow straw vs the weak wall. Arch Facial Plast Surg. 2012 Feb;14(1):9-10.

7. Hellings PW, Scadding G, Alobid I, Bachert C, Fokkens WJ, Gerth van Wijk R, et al. Executive summary of European Task Force document on diagnostic tools in rhinology.
Rhinology. 2012 Dec:50(4):339-52

8. Hens G, Vanaudenaerde BM, Bullens DMA Piessens M, Decramer M, Dupont LJ, et al. Sinonasal pathology in nonallergic asthma and COPD: "united airway disease" beyond the scope of allergy. Allergy. 2008 Mar;63(3):261-7.

9. Ottaviano G, Fokkens WJ. Measurements of nasal airflow and patency: a critical review with emphasis on the use of peak nasal inspiratory flow in daily practice. Allergy. 2016 Feb;71(2):162-74.

10. Ng BA, Mamikoglu B, Ahmed MS, Corey JP. The effect of external nasal dilators as measured by acoustic rhinometry. Ear Nose Throat J. 1998 Oct;77(10):840-4.

11. Peltonen LI, Vento SI, Simola M, Malmberg $H$. Effects of the nasal strip and dilator on nasal breathing--a study with healthy subjects. Rhinology. 2004 Sep;42(3):122-5.

12. Lorino AM, Lofaso F, Drogou I, Abi-Nader F, Dahan E, Coste A, et al. Effects of different mechanical treatments on nasal resistance assessed by rhinometry. Chest. 1998 Jul;114(1):166-70.

13. Griffin JW, Hunter G, Ferguson D, Sillers MJ. Physiologic effects of an external nasal dilator. Laryngoscope. 1997 Sep;107(9):1235-8.

14. Bourdin M, Sallet P, Dufour A-B, Lacour J-R.
Influence of changes in nasal ventilation on estimated workload during submaximal field running. J Sports Med Phys Fitness. 2002 Sep;42(3):295-9.

15. Petruson B, Theman K. Clinical evaluation of the nasal dilator Nozovent. The effect on snoring and dryness of the mouth. Rhinology. 1992 Dec;30(4):283-7.

16. Metes A, Cole P, Hoffstein V, Miljeteig H Nasal airway dilation and obstructed breathing in sleep. Laryngoscope. 1992 Sep;102(9):1053-5.

17. Ulfberg J, Fenton G. Effect of Breathe Right nasal strip on snoring. Rhinology. 1997 Jun;35(2):50-2.

18. McLean HA, Urton AM, Driver HS, Tan AKW Day AG, Munt PW, et al. Effect of treating severe nasal obstruction on the severity of obstructive sleep apnoea. Eur Respir J. 2005 Mar;25(3):521-7.

19. Gosepath J, Amedee RG, Romantschuck S, Mann WJ. Breathe Right nasal strips and the respiratory disturbance index in sleep related breathing disorders. Am J Rhinol. 1999 Oct;13(5):385-9.

20. Raudenbush B. Stenting the nasal airway for maximizing inspiratory airflow: internal Max-Air Nose Cones versus external Breathe Right strip. Am J Rhinol Allergy. 
2011 Aug;25(4):249-51.

21. Sadan O, Shushan S, Eldar I, Evron S, Lurie $\mathrm{S}$, Boaz M, et al. The effects of an external nasal dilator on labor. Am J Rhinol. 2005 Apr;19(2):221-4.

22. Neuenschwander H, Molto A, Bianchi M External nasal dilator strips (ENDS) may improve breathlessness in cancer patients. Support Care Cancer. 2006 Apr;14(4):386-8.

23. Salturk Z, Inan M, Kumral TL, Atar Y, Yildirim G, Uyar Y. Efficiency of external nasal dilators in pediatric nasal septal deviation. Int J Pediatr Otorhinolaryngol. 2014 Sep;78(9):1522-5.

24. Meltzer EO, Johnson S. Objective and subjective responses to a mechanical external nasal dilator in healthy children and children with nasal congestion. Allergy Asthma Proc. 2015 Dec;36(6):481-6.

25. Roithmann R, Chapnik J, Zamel N, Barreto SM, Cole P. Acoustic rhinometric assessment of the nasal valve. Am J Rhinol. 1997 Oct;11(5):379-85.

26. Riechelmann H, Karow E, DiDio D, Kral F. External nasal valve collapse - a case-control and interventional study employing a novel internal nasal dilator (Nasanita). Rhinology. 2010 Jun;48(2):183-8.

27. Gruber RP, Lin AY, Richards T. Nasal strips for evaluating and classifying valvular nasal obstruction. Aesthetic Plast Surg. 2011 Apr;35(2):211-5.

28. Hellings PW, Nolst Trenité GJ. Long-term patient satisfaction after revision rhinoplasty. Laryngoscope. 2007 Jun;117(6):985-9.

29. Latte J, Taverner D. Opening the nasal valve with external dilators reduces congestive symptoms in normal subjects. Am J Rhinol. 2005 Apr;19(2):215-9.

30. Höijer U, Ejnell H, Hedner J, Petruson B, Eng LB. The effects of nasal dilation on snoring and obstructive sleep apnea. Arch Otolaryngol Head Neck Surg. 1992 Mar;118(3):281-4.

31. Kirkness JP, Wheatley JR, Amis TC. Nasal airflow dynamics: mechanisms and responses associated with an external nasal dilator strip. Eur Respir J. 2000 May;15(5):929-36.

32. Passàli D, Mezzedimi C, Passàli GC, Nuti D, Bellussi $L$. The role of rhinomanometry, acoustic rhinometry, and mucociliary transport time in the assessment of nasal patency. Ear Nose Throat J. 2000 May;79(5):397400.

33. Lam DJ, James KT, Weaver EM. Comparison of anatomic, physiological, and subjective measures of the nasal airway. Am J Rhinol. 2006 Oct;20(5):463-70.

34. Scadding G, Hellings P, Alobid I, Bachert C, Fokkens W, van Wijk RG, et al. Diagnostic tools in Rhinology EAACl position paper. Clin Transl Allergy. 2011;1 (1):2.

35. Palesy T, Pratt E, Mrad N, Marcells GN Harvey RJ. Airflow and patient-perceived improvement following rhinoplastic correction of external nasal valve dysfunction.
JAMA Facial Plast Surg. 2015 Apr;17(2):131-

36. Seren $E$. The effect of an adhesive external nasal dilator strip on the inspiratory nasal airflow. Am J Rhinol Allergy. 2010 Feb;24(1):e29-31.

37. Pertuze J, Watson A, Pride NB. Maximum airflow through the nose in humans. J Appl Physiol. 1991 Mar;70(3):1369-76.

38. Shaida AM, Kenyon GS. The nasal valves: changes in anatomy and physiology in normal subjects. Rhinology. 2000 Mar;38(1):712.

Peter W. Hellings, MD, PhD

Department of Otorhinolaryngology

Head and Neck Surgery

University Hospitals Leuven

Kapucijnenvoer 33

3000 Leuven

Belgium

Tel: $+32-16332338$

Fax: +32-1634 6035

E-mail:

peter.hellings@med.kuleuven.be 